\title{
Evidence for extreme pressure pulses in the subglacial water system
}

\author{
Jeffrey L. Kavanaugh, Garry K.C. Clarke, \\ Department of Earth and Ocean Sciences, University of British Columbia, Vancouver, British Columbia V6T 124, Canada
}

\begin{abstract}
A suite of subglacial water-pressure records from the 1996 summer field season at Trapridge Glacier, Yukon Territory, Canada, discloses a hydraulic event that cannot readily be explained by known forcings. We suggest that these records indicate covert failure of the pressure sensors caused by at least one large water-pressure pulse. The sign and magnitude of the pulse appears to have varied spatially and the pulse duration was less than the 2 min sampling interval of our data loggers. Laboratory experiments support this interpretation and indicate that the pulse magnitude exceeded $900 \mathrm{~m}$ of hydraulic head, roughly 15 times the ice-overburden pressure. Within glaciers, large water-pressure pulses can be generated when abrupt ice motion changes the volume of the subglacial hydraulic system.
\end{abstract}

\section{INTRODUGTION}

We present a suite of subglacial instrument records taken during the summer 1996 field season at Trapridge Glacier, Yukon Territory, Canada. Interpreted literally, these records provide evidence for a hydraulic transformation that seems impossible to reconcile with current understanding of subglacial processes. Although strong responses were recorded by 12 of the 14 operating pressure transducers, other sensors were unaffected by the event or recorded only minor signals. The paradoxical instrument records can be explained by transient pressure pulses in the subglacial water system. Exposure to such a pressure pulse can permanently deform the measurement diaphragm of a transducer, causing an apparent shift in calibration. In field records, this calibration shift would appear as a pressure jump that might be difficult to distinguish from hydraulically plausible behaviour. Laboratory studies confirm that overpressurization of pressure transducers can cause calibration resetting, and modelling of this form of sensor failure yields simulated responses that are qualitatively similar to the puzzling records from Trapridge Glacier. Analysis of other instrument records suggests that transient water-pressure pulses could be generated by abrupt glacier motion that compresses or dilates the subglacial hydraulic system. In the instrumented region, mechanical signals lag the pressure changes by several minutes, implying that the inferred pressure pulses may induce basal motion.

\section{OBSERVATIONS}

Since 1988 we have recorded year-round measurements of water pressure beneath Trapridge Glacier (Fig. 1) in an effort to broaden understanding of subglacial hydraulic phenomena (see Clarke and Blake (1991) for background information and references). Fourteen pressure transducers were in operation on 20 July 1996. Map locations for the six sensors detailed in

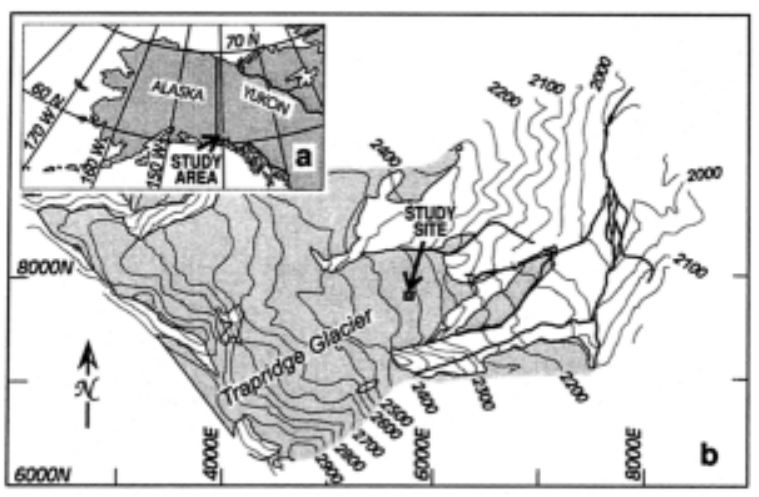

Fig. 1. Study area. (a) Location map, southwestern Yukon Territory, Canada. (b) Trapridge Glacier, showing location of instrument study site.

this study are presented in Figure 2. Five of the six sensors were installed in July 1996; the sixth was installed in July 1995 and its position has been corrected for glacier motion. Four pressure sensors that were placed in hydraulically connected regions of the bed, as indicated by water-level fluctuations in the borehole immediately after drilling was completed, are identified as $\mathrm{Cl}-\mathrm{C} 4$; two sensors that were placed in hydraulically unconnected holes are denoted U1 and U2. These designations do not necessarily correspond to the connection status at later times. Also included in Figure 2 are corrected locations for two ploughmeters, installed in July 1995 and labelled PL1 and PL2, and two 1996 geophones, designated $\mathrm{Gl}$ and G2.

Before installation in Trapridge Glacier, pressure transducers are typically built into hydrology units that combine pressure, conductivity and turbidity sensors into one device. In these units, the pressure sensor is situated slightly up-hole from the other sensors, and all sensors share a common signal wire. Hydrology units are installed approximately $0.15 \mathrm{~m}$ above the bed. Transducers installed in-hole with ploughmeters (Fischer and Clarke, 1994) are placed $\sim 2 \mathrm{~m}$ above the bed. Boreholes typically freeze 


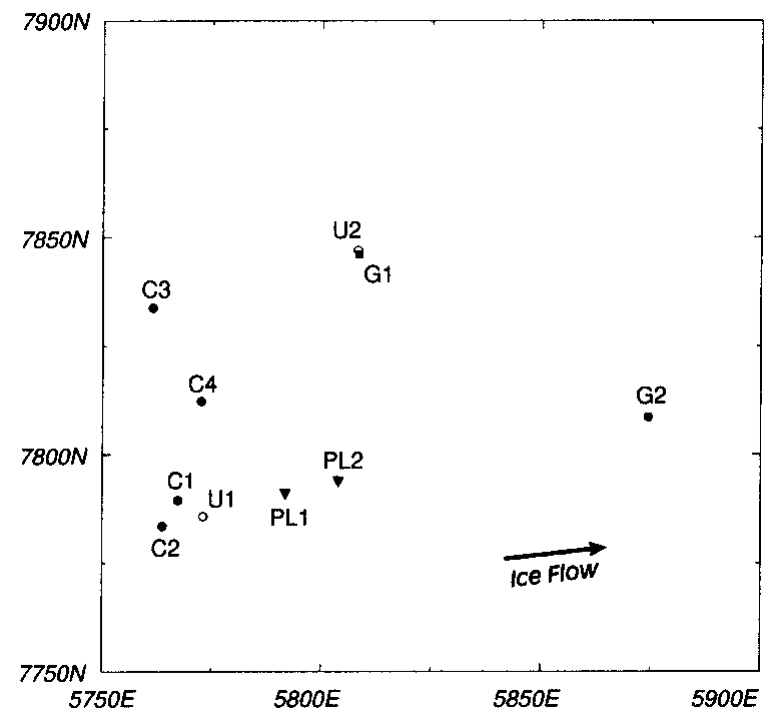

Fig. 2. Study site. Coordinates are given in metres easting and northing, with positions of instruments installed in 1995 corrected for glacier flow.

closed near the surface within $\sim 1$ day, thus confining the instruments in a closed water-filled space.

Figure 3 shows 12 day records for three pressure transducers installed $<10 \mathrm{~m}$ apart (Fig. 2). Pronounced changes in pressure are recorded by sensors $\mathrm{C} 2$ and $\mathrm{U} 1$ near the end of day 202. The pressure records of $\mathrm{Cl}$ and C2 (Fig. 3a and b, respectively) show close agreement for the first 7 days of observation. Pressure values indicated by $\mathrm{Cl}$ are consistently $0.72 \mathrm{~m}$ higher than those for $\mathrm{C} 2$, even for high-frequency pressure fluctuations that are barely discernible on the two records. Peak pressures are close to the local ice flotation value of $\sim 60 \mathrm{~m}$. At $2120 \mathrm{~h}$ on day 202 the pressure record for C2 shows a sharp increase of $29.7 \mathrm{~m}$, while that for C1 gives no indication of this jump. Subsequently, the pressure records continue to show close agreement in both diurnal variation and fine detail, but with a pressure offset of $+28.5 \mathrm{~m}$ for $\mathrm{C} 2$, indicating peak pressures well above flotation. The pressure record for U1 (Fig. 3c) shows a diurnal signal having lower amplitude than, and opposite phase to, those for C1 and C2. Such contrasts between the behaviour of connected and unconnected regions are not unusual and result from the transfer of mechanical support

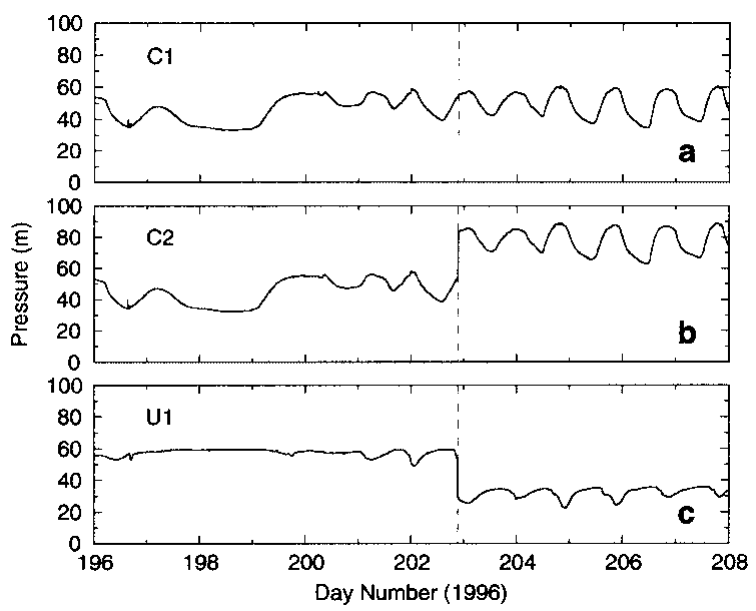

Fig. 3. Pressure records. Day 196 corresponds to 14 July 1996. Vertical dashed lines represent $2120 h$ on day 202. (a) Connected transducer C1. (b) Connected transducer C2. (c) Unconnected transducer $U 1$. of ice overburden between the two regions as the watersystem pressure varies (Murray and Clarke, 1995; Gordon and others, 1998). At $2120 \mathrm{~h}$ on day 202, coincident with the abrupt change in the pressure record for C2, sensor U1 indicates a pressure drop of $23.9 \mathrm{~m}$. The diurnal character of the record is unaffected by this pressure step.

Twelve of the fourteen pressure transducers in operation on 20 July 1996 showed responses at the time of the event that affected sensors C2 and U1. Responses ranged from a pressure increase of $0.5 \mathrm{~m}$ recorded by one sensor to the apparent failure of three transducers, and were recorded throughout the $200 \mathrm{~m} \times 250 \mathrm{~m}$ instrumented study area. Figure $4 \mathrm{a}^{-} \mathrm{c}$ show details of records for the six pressure transducers shown in Figure 2 over a 3 day period spanning the hydraulic event. These records demonstrate the wide range of responses seen in pressure records at the time of the event. Pressure records for C2 and C3 are shown in Figure $4 \mathrm{a}$, with that for $\mathrm{Cl}$, the unaffected sensor, included
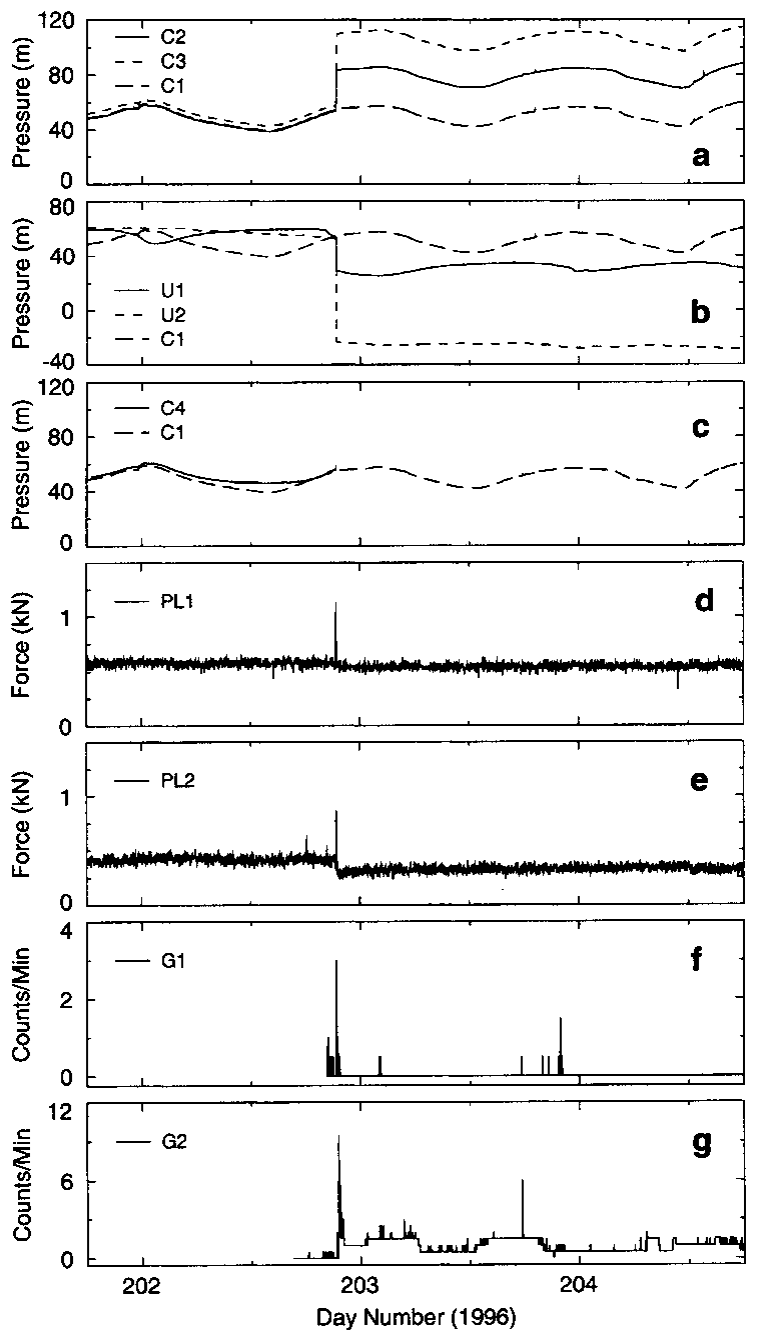

Fig. 4. Detailed instrument records. (a) Time-series plots for connected transducers C2 (solid line), C3 (short-dashed line) and C1 (long-dashed line). (b) Unconnected transducers U1 (solid line) and U2 (short-dashed line), compared to C1 (long-dashed line). (c) Comparison of C4 (solid line) to C1 (dashed line). Failure of C4 occurs at 2120 h on day 202. (d) Force record for ploughmeter PL1. Transient peak occurs at 2124 h, day 202. (e) Force record for PL2. Transient peak occurs at 2124 h, day 202. (f) Geophone G1. Small peak occurs at 2122 h, day 202. (g) Geophone G2. Small peak noted at time of event; larger peak of $9.5 \mathrm{~min}^{-1}$ occurs at 2134 h, day 202. 
as a reference. Sensor C3 was installed $44.8 \mathrm{~m}$ cross-glacier from Cl (Fig. 2). All three boreholes connected to the subglacial hydrological system at the time of drilling. Despite the distance between sensors, C2 and C3 show comparable behaviours: (i) initially, both pressure signals have similar form but are slightly offset from that of $\mathrm{Cl}(-0.72 \mathrm{~m}$ for $\mathrm{C} 2$; $+3.0 \mathrm{~m}$ for C3); (ii) C2 and C3 exhibit large jumps in recorded pressure at $2120 \mathrm{~h}$ on day 202; (iii) subsequent pressure fluctuations are very similar to that of $\mathrm{Cl}$ but with large offsets (+ $28.4 \mathrm{~m}$ for $\mathrm{C} 2,+55.2 \mathrm{~m}$ for $\mathrm{C} 3)$.

Pressure records for $\mathrm{U} 1$ and $\mathrm{U} 2$ are shown in Figure $4 \mathrm{~b}$. Both instruments were installed in boreholes that were hydraulically unconnected to the drainage system at the time of drilling. Sensor U2 was installed $70.6 \mathrm{~m}$ down-glacier from Cl (Fig. 2). The unconnected records exhibit higher ambient pressures and lower variability than those for the connected holes. Coincident with the pressure increases of C2 and C3, both sensors show marked decreases in pressure, with U2 recording negative pressure values after the drop. All pressure decreases associated with the event were recorded by transducers installed in unconnected regions of the bed, whereas the majority of connected sensors exhibited positive pressure jumps at the time of the event.

Figure 4c compares the response of $\mathrm{Cl}$ to $\mathrm{C} 4$, a transducer installed in 1995. The advected position of C4 is calculated from surface flow measurements. The two records show similar diurnal character, indicating C4 is sampling a connected region of the bed, though the damped diurnal signal of C4 suggests an imperfect hydraulic connection with C1. Failure of C4 occurs at the time of the sudden pressure change observed by the other sensors. Two of the three event-related transducer failures were of sensors installed in connected regions of the bed.

In contrast to the strong responses recorded by pressure transducers, other instruments showed only minor responses to the event. No conductivity or turbidity records exhibit changes at the time of the event; similarly, none of the tilt cells or slidometers (Blake and others, 1994) recorded any event response. Of the 14 ploughmeters installed, two displayed small transient responses shortly after the event. Ploughmeters PLl (Fig. 4d) and PL2 (Fig. 4e) were installed in 1995. Their positions, corrected for glacier flow, are shown in Figure 2. Records for ploughmeters are characterized by low, steady force values, averaging $0.56 \mathrm{kN}$ for PLl and $0.41 \mathrm{kN}$ for PL2. Both ploughmeters recorded small transient peaks 4 min after the event, measuring $1.13 \mathrm{kN}$ for PLl and $0.87 \mathrm{kN}$ for PL2. Both ploughmeters return to steady forcings after the transient peak, with PL2 measuring a slight reduction in force at $0.28 \mathrm{kN}$. Five of the eight geophones produced increased count rates near the time of the event. Although three geophones registered counts during the event interval, peak count rates occurred 2-20 min after the event. Icequake count rates for geophones G1 and G2 are shown in Figure $4 \mathrm{f}$ and $\mathrm{g}$. Both were installed on day 201 and were allowed to freeze into the glacier ice before being connected to data loggers on day 202; their locations are shown in Figure 2. While no counts are measured by G1 during the 2 min interval preceding the event, a small peak of $3 \mathrm{~min}^{-1}$ is recorded immediately afterward (Fig. 4f). Counts are recorded for a $24 \mathrm{~min}$ period following the event. Sensor G2 (Fig. 4g) registers a small peak of $2 \mathrm{~min}^{-1}$ during the interval immediately prior to the event, followed by a count rate of $9.5 \mathrm{~min}^{-1} 14 \mathrm{~min}$ later. Elevated count rates continue until approximately $46 \mathrm{~min}$ after the event.

\section{INTERPRETATION}

The instrument records presented in Figures 3 and 4 suggest an event having both hydrological and mechanical components. Timing of the various sensor responses suggests that, at least in the instrumented region of the bed, the hydrological signal preceded the mechanical response by several minutes. We therefore focus on the pressure-transducer records, and explore the implications of two alternative hypotheses: (i) that the curious behaviour can be explained in terms of a rapid change in the subglacial drainage morphology, and (ii) that rapid and extreme water-pressure variations, undetected because of the 2 min sampling interval of our data loggers, have reset the calibrations of four of the five sensors subjected to the extreme event.

\section{Drainage morphology implications}

Individually, the three pressure records presented in Figure 3 imply plausible changes in the local subglacial water pressure. Taken together, they suggest the occurrence of an intriguing hydrological switching event that led to highly localized reorganization of the subglacial water-pressure field. In Figure $4 \mathrm{a}$, the small initial pressure offsets can be attributed to differences in bed elevation or errors in measurement of transducer installation depth. Similarities in the pressure signals, including both diurnal and small-scale character, indicate the presence of an efficient low-resistance connection between boreholes both before and after the event. Weakening of the connection during the event would result in differences in amplitude or phase of the diurnal signal between sensor records, or reduced coherence of small-scale features. Instead, following the switching event, the three pressure records of Figure 4a show nearly identical waveforms but with large constant pressure offsets.

Figure 5 illustrates a hydraulic reorganization that could account for the observed features in the records of C1-C3. For clarity, the system is represented by water pipes and shows three branches of a subglacial drainage system, each branch representing a region measured by an individual pressure transducer. The similar elevation and strong hydraulic connection evident in the pipe circuit of Figure 5a would ensure uniform responses to variations in pressure head and could therefore reproduce the essential features of the pre-event records for Cl-C3. Switching to the pipe geometry shown in
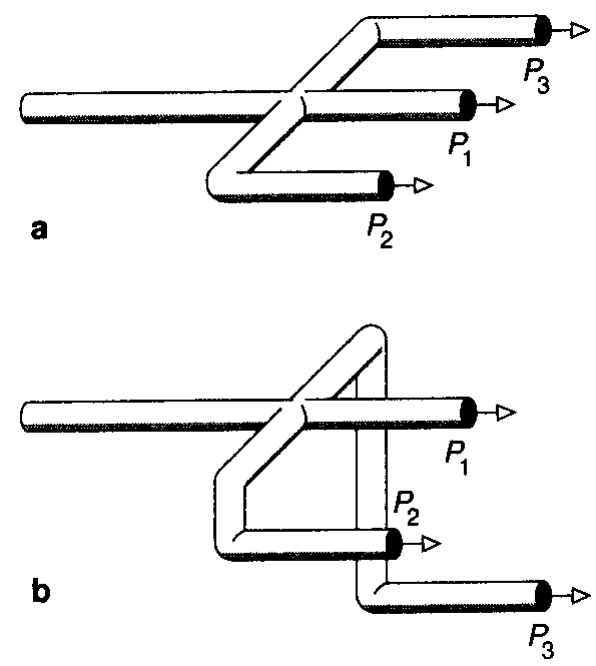

Fig. 5. Schematic diagram showing hydraulic connections which could explain the pressure records of transducers C1-C3. (a) Before event. (b) After event. 
Figure $5 \mathrm{~b}$ would produce offsets resembling those of the observed post-event records. Lowering two of the branches by distances $\triangle h_{2}$ and $\triangle h_{3}$ yields pressures $P_{2}=P_{1}+\triangle h_{2}$ and $P_{3}=P_{1}+\triangle h_{3}$. Pressure $P_{1}$ is unaffected by the event. The low-resistance pipe allows the strong hydraulic connection to be maintained, and thus each transducer measures similar pressure fluctuations while exhibiting large offsets. Although this simple scenario reproduces the main features of the connected sensor records, it cannot occur subglacially. The pipes shown in Figure 5 represent drainage pathways at the glacier bed, and thus the sudden drops in elevation of 29.2 and $52.2 \mathrm{~m}$ indicated in the records of C2 and C3 would place the drainage channels deep within the glacier bed. Furthermore, movement of the drainage channels alone is insufficient to produce the observed offsets: it is necessary for the transducers to change elevation as well. Up-thrusting of the sensors is a conceivable process, but down-thrusting through the bed is certainly not.

Subglacial pressure signals have been attributed to both hydrological forcings, including changes in meltwater input and drainage morphology (e.g. Fountain, 1994; Walder and Fowler, 1994; Clarke, 1996), and mechanical forcings, such as the transfer of overburden pressure between regions of the bed (Murray and Clarke, 1995). The failure of current hydrological models to explain the transducer records compels us to ask whether the observed offsets are maintained by forcings that have thus far eluded understanding, or if the signals can be more simply attributed to other causes, such as instrument failure. The record for transducer $\mathrm{U} 2$ argues in favour of the latter explanation. Sensors U1 and U2 (Fig. 4b) were installed in hydraulically unconnected regions of the bed, and both records exhibit low-amplitude pressure variations that are out of phase with those of $\mathrm{Cl}-\mathrm{C} 4$. At the time of the switching event, both sensors record large pressure decreases, but the character of the diurnal variations in each case is unchanged by the event. While U1 records reasonable pressure values following the event, the negative post-event values recorded by $\mathrm{U} 2$ suggest instrument failure and raise several questions: (i) Are the other observed pressure jumps due to device failure? (ii) If so, what is the failure mechanism? (iii) Is this mechanism also responsible for the failure of $\mathrm{C} 4$ ?

\section{Implications of covert sensor failure}

In order to discuss the failure of pressure sensors, it is first necessary to describe their operating principles. A schematic diagram of the transducer (Gems Sensors Series 2000, 16 bar absolute) is shown in Figure 6. Variations in water pressure deflect the measurement diaphragm, which in turn bends the sensor beam (Fig. 6a). Pressures are measured relative to a sealed reference chamber (Fig. 6b). Transducer response is highly linear with changes in water pressure over the specified measurement range, and thus the relation $V=a_{0}+a_{1} h$, which we refer to as the sensor-response equation, provides an excellent fit to the calibration data. Here $V$ is the output of the transducer measured in millivolts, and $h$ is the hydraulic head expressed in metres above the bed. To determine the pressure head for a given transducer output, the sensor-response equation is inverted to give the sensor-calibration equation $h=b_{0}+b_{1} V$, where, self-evidently, $b_{0}=-a_{0} / a_{1}$ and $b_{1}=1 / a_{1}$. A transducer excitation voltage of $2.5 \mathrm{~V}$ was used in all field measurements

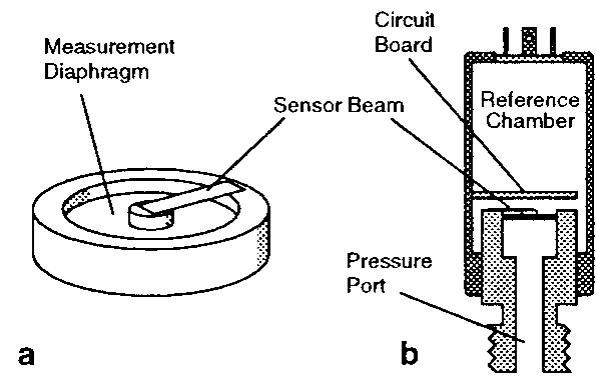

\section{Fig. 6. Schematic diagram of pressure transducer. (a) Detail of measurement diaphragm and sensor beam, shown at approximately $2 \times$ scale. (b) Cross-section, shown at approximately $1 / 2$ scale.}

and laboratory studies, and data were recorded using a sampling interval of 2 min on Campbell CR10 data loggers.

The event affected a large number of transducers, covering a large area and connected to several different data loggers; thus the failures cannot be attributed to simple electrical problems. Lightning strikes, which could potentially affect several loggers simultaneously, would be expected to induce some signature in turbidity and conductivity records as well. Such signals are not observed. Three of the six pressure transducers involved in this study were incorporated into hydrology units. While the turbidity and conductivity sensors installed with $\mathrm{C} 4$ were disconnected prior to the event and thus give no indication of the failure mode, those sensors installed with $\mathrm{C} 3$ and $\mathrm{U} 2$ were operating at the time, and no reflection of the event is evident in these records. Thus, crushing of the instruments or wire breakage could not explain the observed pressure records.

We propose a mode of transducer failure that reconciles the seemingly incompatible instrument records. Transient high-pressure pulses, having peak pressures well above the specified transducer measurement range, can impose a permanent strain on the measurement diaphragm. This damage results in an effective shift in the response coefficients $a_{0}$ and $a_{1}$. Recalibration of a transducer after exposure to a highpressure pulse would yield new values of calibration coefficients $b_{0}$ and $b_{1}$. However, because the original values continue to be used, the calculated pressure fluctuations have incorrect amplitude and offset.

We conducted a series of laboratory experiments to test the validity of the failure hypothesis. Two pressure transducers, identified as PT1 and PT2 and of identical manufacture to those installed in Trapridge Glacier, were calibrated over the range $0-700 \mathrm{kPa}(0-71.4 \mathrm{~m})$ at $100 \mathrm{kPa}$ $(10.2 \mathrm{~m}$ ) intervals (all pressures measured relative to atmospheric). Two measurements were taken at each calibration point, first as the pressure was increased from atmospheric to the maximum value and then again as it was released. The lack of hysteresis in these data indicates that the calibration was unaffected by fluctuations in ambient temperature or by adiabatic heating of the air-pressure chamber during testing. After calibration, the transducers were subjected to static pressure values of $1200-17000 \mathrm{kPa}$ $(122-1730 \mathrm{~m})$ at intervals of $500-1000 \mathrm{kPa}(51-102 \mathrm{~m})$ using a hydraulic hand pump (Enerpac Model P-39). These values represent pressures well above both the rated transducer pressure limit of $1600 \mathrm{kPa}$ and typical ambient subglacial pressures of 300-800 kPa measured beneath Trapridge Glacier. The pressures were sustained only long enough to record the transducer output (typically $0.5-1.5 \mathrm{~min}$ ). We shall refer to the 
extreme pressure $P^{*}$ to which a transducer has been subjected as the inherited extreme pressure or "damage pressure". Accepting the sensor-failure hypothesis, the sensor-response equation is rewritten as $V=a_{0}\left(P^{*}\right)+a_{1}\left(P^{*}\right) h$, where the damagedsensor-response parameters are assumed to depend on the device history, encapsulated in $P^{*}$.

The transducers were recalibrated each time that the damage pressure was increased, and changes in response parameters $a_{0}$ and $a_{1}$ were noted. Output voltages are plotted against calibration pressure for PT1 and PT2 in Figure $7 \mathrm{a}$ and b, respectively. Each line represents a sensor calibration performed at successively higher values of damage pressure. After being subjected to high damage pressures, both transducers yielded an increased voltage response for a given calibration pressure. This results in an upward shift of the calibration line and effectively changes $a_{0}$ to a greater value.

If the calibration line is shifted sufficiently, the transducer can produce output voltages that are greater than the maximum value measurable by the data logger. As programmed for our experiments, the Campbell data logger cannot measure voltages exceeding $\sim 27 \mathrm{mV}$. Figure 7 shows that damage pressures greater than approximately $15000 \mathrm{kPa}(1530 \mathrm{~m})$ can cause calibration shifts sufficient to yield out-of-range output voltages for typical values of subglacial water pressure for Trapridge Glacier. The failure of C4 (Fig. 4c) could thus also be explained by a large pressure pulse.

If the ambient hydraulic head is $h=0 \mathrm{~m}$, the damagedsensor-response equation yields a voltage of $V=a_{0}\left(P^{*}\right)$. Applying this voltage to the sensor-response equation gives an indicated hydraulic head $h^{*}=b_{0}+b_{1} a_{0}\left(P^{*}\right)$, which for damaged sensors differs from $h=0 \mathrm{~m}$ and constitutes a calibration offset. In Figure 8a, this calibration offset, $h^{*}$, is plotted against damage pressure. Shifts are first observed at damage pressures as low as $2000 \mathrm{kPa}$ (205 m). Below $\sim 4000 \mathrm{kPa}(410 \mathrm{~m})$, increases in damage pressure produce small calibration shifts (see inset, Fig. 8a). Above this threshold, increases in damage pressure result in large calibration offsets; for both sensors the form of the relationship approximates an exponential increase in $a_{0}\left(P^{*}\right)$ with increasing damage pressure. If transducers installed in Trapridge Glacier fail in a comparable manner, we can estimate the magnitude of the pressure pulses responsible for the offsets in the records of $\mathrm{C} 2$ and $\mathrm{C} 3$ from

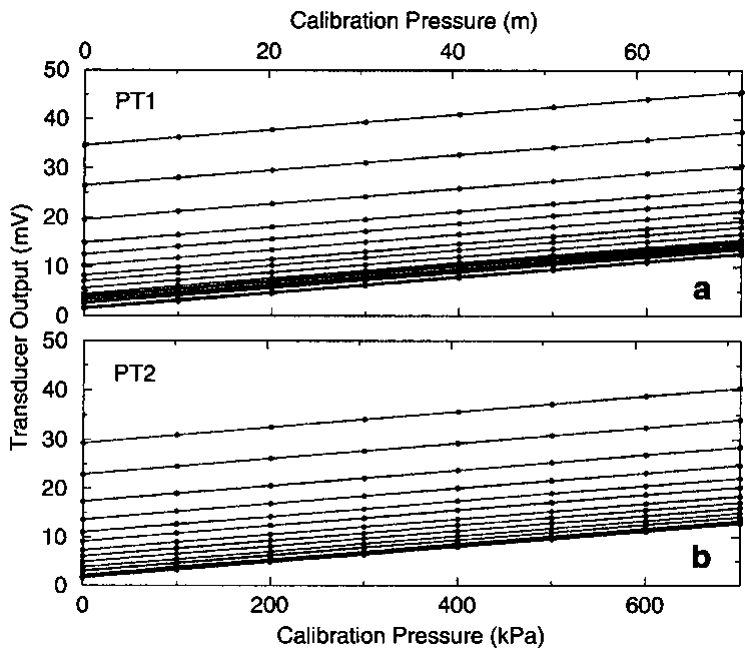

Fig. 7. Repeated calibration data. Transducers were exposed to an increased damage pressure between calibrations. (a) PT1. (b) PT2.
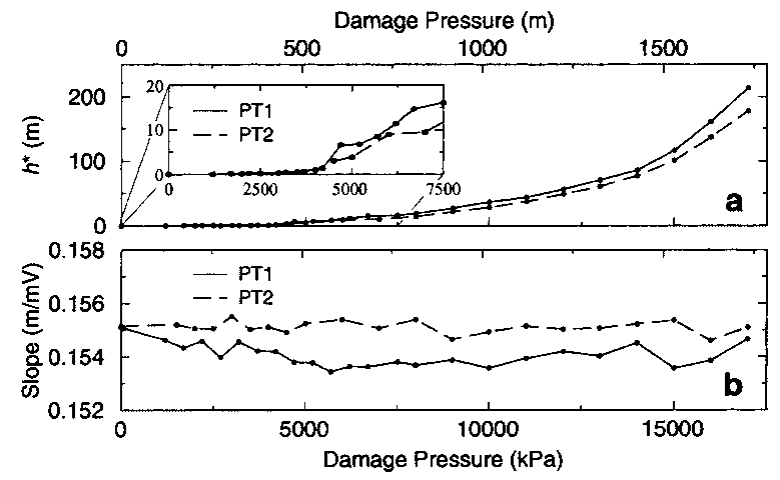

Fig. 8. (a) Plot of calibration offset $h^{*}$ against damage pressure for PT1 (solid line) and PT2 (dashed line). Inset: detail of calibration shift at low damage pressures. (b) Plot of calibration slope value against damage pressure.

these experimental results. The $29.2 \mathrm{~m}$ shift in the time series of $\mathrm{C} 2$ corresponds to a pulse on the order of 9000-11000 kPa (900-1100 m), with the $52.2 \mathrm{~m}$ shift of C3 requiring a pulse of approximately $11000-13000 \mathrm{kPa} \quad(1100-1300 \mathrm{~m})$. If we attribute the failure of $\mathrm{C} 4$ to pressure-induced calibration shift to an off-scale value, Figure 8a suggests that the pulse pressure was greater than $\sim 15000 \mathrm{kPa}(1500 \mathrm{~m})$. While the transducers in this experiment were subjected to multiple damage pressures of increasing value, calibration shifts observed in field records probably resulted from a single pressure pulse. Thus the calibration offset behaviour of a transducer installed in the field might differ from those observed in this laboratory study.

The parallelism of the calibration lines in Figure 7 suggests that the slope of the calibration line (calibration coefficient $a_{1}$ ) does not change significantly with increasing damage pressure. Figure $8 \mathrm{~b}$ plots the calibration-line slope against damage pressure. The pre-damage $\left(P^{*} \sim 0\right)$ values of the calibration slope for the two transducers are very similar at $a_{1}(0)=0.1551 \mathrm{mV} \mathrm{m}^{-1}$ for both PT1 and PT2. With increasing damage pressure, $\mathrm{PT} 1$ shows a small overall decrease in value, while PT2 varies slightly around the initial pre-damage value. The maximum deviation of $a_{1}$ during damage-pressure testing for PT1 occurs at $P^{*}=5700 \mathrm{kPa}$, with $a_{1}\left(P^{*}\right)=0.1534 \mathrm{mV} \mathrm{m}^{-1}$; the maximum deviation of PT2 gives $a_{1}\left(P^{*}\right)=0.1546 \mathrm{mV} \mathrm{m}^{-1}$ at $P^{*}=16000 \mathrm{kPa}$. These values represent changes in slope of $-1.07 \%$ and $-0.35 \%$, respectively, and may indicate strain hardening due to diaphragm damage (personal communication from P. Jansson, 1999). The calibration constants $b_{0}$ and $b_{1}$ of the sensor-response equation are calculated from the initial pre-damage calibration values $a_{0}(0)$ and $a_{1}(0)$, and thus any change in $a_{1}\left(P^{*}\right)$ results in the scaling of the apparent magnitude of a given pressure signal by the factor $a_{1}\left(P^{*}\right) / a_{1}(0)$. For example, a pulse of magnitude $P^{*}=5700 \mathrm{kPa}$ would reduce the response of sensor PT1 to a $20 \mathrm{~m}$ pressure fluctuation by $0.215 \mathrm{~m}(-1.07 \%)$.

As a consequence of the effective changes in $a_{0}$ and $a_{1}$, the record of an instrument subjected to a high-pressure pulse would appear to abruptly jump to a higher ambient pressure, while the magnitude of diurnal and small-scale fluctuations would change only slightly. Although sudden pressure jumps are easy to recognize in instrument records, small changes in the amplitude of pressure fluctuations are difficult to discern unless the record for an undamaged transducer is available for comparison. Sensors C2 and C1 provide such a complementary pair of field records. In 

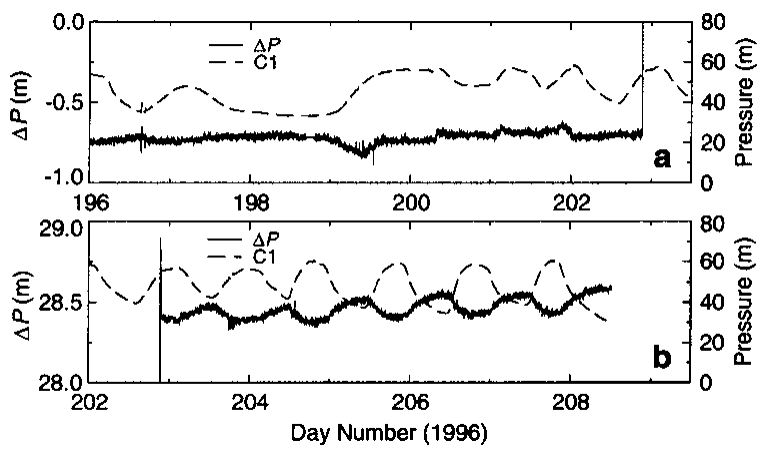

Fig. 9. Pressure difference between C2 and C1. Time series for C1 (dashed line) is shown for comparison. (a) Detail before event. (b) Detail after event.

Figure 9 the pressure difference between the two sensors, $\Delta P=P_{\mathrm{C} 2}-P_{\mathrm{C} 1}$, is plotted. The pressure record of $\mathrm{Cl}$ (dashed line) is shown for comparison. Prior to the event of $2120 \mathrm{~h}$ on day 202 (Fig. 9a), C2 registers pressures approximately $0.72 \mathrm{~m}$ lower than those measured by $\mathrm{Cl}$. Slight deviations from this value (e.g. accompanying the large pressure increase on day 199 and at peak pressure on days 201 and 202) show no systematic relationship between $P_{\mathrm{C} 1}$ and $\Delta P$. After the event (Fig. 9b), $\Delta P$ varies sinusoidally around $28.4 \mathrm{~m}$ with a peak-to-peak amplitude of $0.154 \mathrm{~m}$. This variation is out of phase with $P_{\mathrm{C} 1}$ and suggests a slight decrease in post-event sensitivity to the $24.9 \mathrm{~m}$ diurnal pressure variation measured by $\mathrm{C} 2$. The measured difference of $-0.151 \mathrm{~m}$ suggests a pressure-pulse-induced deviation in $a_{1}$ of $-0.606 \%$, comparable in value to changes exhibited by the transducers during laboratory testing.

To further investigate this behaviour, we model the response of PTl to a diurnal sinusoidal pressure fluctuation that varies between 40 and $60 \mathrm{~m}$ (Fig. 10a). The voltage response is calculated by applying the pre-damage values $a_{0}(0)=1.4316 \mathrm{mV}$ and $a_{1}(0)=0.1551 \mathrm{mV} \mathrm{m}^{-1}$ to the damaged-sensor-response equation.Substituting the resulting voltage into the sensor-response equation, with $b_{0}=-a_{0}(0) / a_{1}(0)$ and $b_{1}=1 / a_{1}(0)$, yields the calibrated instrument output. To simulate the occurrence of a

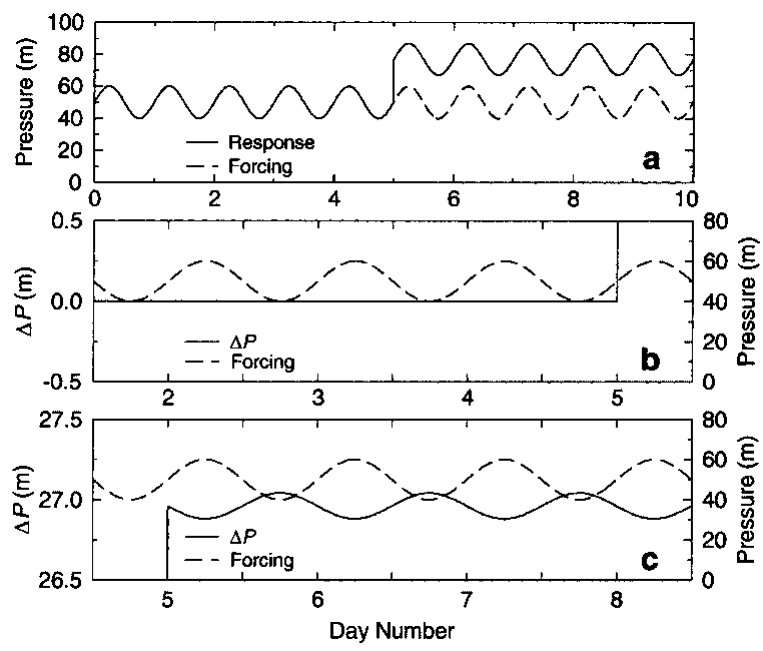

Fig. 10. (a) Modelled response of PT1 to a sinusoidally varying pressure function with a $9000 \mathrm{kPa}(918 \mathrm{~m})$ pressure pulse at $0 h$ on day 5 . The modelled input pressure is plotted as a dashed line. (b, c) Pressure difference between modelled instrument response and input pressure. Input pressure (dashed line) shown for comparison. (b) Detail before pulse. (c) Detail after pulse.
$P^{*}=9000 \mathrm{kPa}(918 \mathrm{~m})$ pressure pulse at $0000 \mathrm{~h}$ on day 5 , we calculate the voltage response of the transducer by switching to the appropriate values of $a_{0}\left(P^{*}\right)=5.675 \mathrm{mV}$ and $a_{1}\left(P^{*}\right)=0.1539 \mathrm{mV} \mathrm{m}^{-1}$ in the damaged-sensor-response equation. This results in a post-event jump of $+27.0 \mathrm{~m}$ in the calibrated output. Figure $10 \mathrm{~b}$ details $\Delta P$ before the modelled pulse. Because the values $a_{0}(0)$ and $a_{1}(0)$ are used both in determining the transducer voltage response and in calculating the corresponding pressure, the transducer accurately records the forcing pressure, and thus $\Delta P=0$. Similarly, the pre-event field records of $\mathrm{Cl}$ and $\mathrm{C} 2$ (Fig. 9a) show a nearly constant value of $\Delta P$. Figure 10c details $\Delta P$ after the occurrence of the modelled damage pulse at the onset of day 5 . The post-pulse change in $a_{1}$ of $-0.796 \%$ results in a response that is $0.159 \mathrm{~m}$ smaller than the $20 \mathrm{~m}$ forcing. This results in a pressure difference $\Delta P$ that varies sinusoidally around $+27.0 \mathrm{~m}$ and is out of phase with the forcing pressure (dashed line). Comparison with the post-event field records of $\mathrm{Cl}$ and $\mathrm{C} 2$ (Fig. 8b) reveals very similar behaviour.

Although the post-event amplitude reduction recorded by C2 could be explained by a change in the subglacial hydraulic system, the extreme linearity of the effect over the full range of the diurnal pressure variation suggests an instrumental cause. The remarkable similarities between the field records of C2 and Cl and the modelled pressure response of PT1, coupled with the unlikely nature of the hydraulic switching necessary to create the aggregate pressure records, strongly support attribution to transducer failure.

\section{Pressure-pulse generation}

While the weak responses recorded by other instruments fail to reveal the origin of the pressure pulses, they do provide constraints on possible sources. Because no pressure pulse was captured in the records, the duration of the pulse must be shorter than the $2 \mathrm{~m}$ sampling interval of the data loggers. The lack of response from conductivity and turbidity sensors precludes any significant change in the flow regime of subglacial water, and it is thus unlikely that the release of stored water gave rise to the pressure pulses. Additionally, the duration of such a release event would probably span several sampling intervals. There is little evidence for basal motion in the instrumented region at the time of the event. Although three geophones recorded counts during the event interval, it is unclear if these counts signify local basal motion or if the geophones are simply responding to the pressure pulse. No indication of change in sliding or deformation rates is evident in slidometer or tilt-cell records. The majority of ploughmeters, including those installed in-hole with pressure transducers Cl, C2 and U1, do not exhibit any change in measured forcing at the time of the event. The small transient responses measured by PL1 and PL2 (Fig. 4d and e) lag the event time by $4 \mathrm{~min}$ and thus cannot be associated with generation of pressure pulses.

Hydraulic transients have been cited as a source of lowfrequency seismic waves recorded by earthquake seismographs (St. Lawrence and Qamar, 1979). These transients are caused by abrupt changes in water velocity in subglacial conduits and are analogous to the "water-hammer effect" commonly associated with piping systems. Although this mechanism can generate pressure pulses having sufficiently large magnitude and short duration to reproduce the observed instrument responses, it requires the high water 
velocities typically associated with conduit drainage. No evidence for conduit drainage has been found at Trapridge Glacier; water transport is instead thought to be dominated by flow along a permeable horizon of sediments at the icebed interface (Stone, 1993). Inferred flow rates of approximately $0.01-0.1 \mathrm{~m} \mathrm{~s}^{-1}$ (Stone and Clarke, 1996) are too low to produce pressure transients capable of damaging the transducers.

We propose that extreme pressure pulses can be generated by abrupt glacier motion that compresses or dilates the subglacial hydraulic system. While no evidence for local basal motion is indicated by mechanical sensor records, transmission of remotely generated pulses through the hydraulic system seems plausible given the large-scale hydraulic communication evident from the connected transducer records (Fig. 4a). While it is unclear to what degree the hydraulic system is compressed by abrupt basal motion, the low compressibility of water $\left(\beta=5.1 \times 10^{-10} \mathrm{~Pa}^{-1}\right)$ indicates that even a small volume change would result in a large increase in pressure. Because transmission of a pressure pulse does not require significant movement of basal water, little response would be expected in conductivity and turbidity records.

Spatial variations in the hydraulic system could result in modulation of the pulse magnitude, and thus individual pressure transducers would likely be affected differently by any given pulse. Negative pressure pulses are indicated by the large offsets observed in the records for transducers U1 and U2 (Fig. 4b). An extreme pressure pulse in the drainage system could result in the rapid transfer of overburden pressure from unconnected regions of the bed. This sudden drop in overburden pressure could create a strong negative pressure transient in unconnected regions, producing the observed negative transducer offsets. Through these mechanisms, a single pulse could give rise to the differing pressure-sensor responses.

The records of G1 and G2 (Fig. 4e and f) show peak count rates $2-14 \mathrm{~min}$ after the event time, and elevated count rates are measured for as long as $46 \mathrm{~min}$ following the event. Two ploughmeters demonstrate increased forcing 4 min after the abrupt changes in the transducer records. If the observed transient increases can be attributed to basal motion, the records suggest that the pressure transients are able to locally decouple the glacier from its bed and thereby induce basal motion.

\section{CONGLUSIONS}

We have identified a mode of pressure-transducer failure that clarifies the interpretation of records that otherwise challenge understanding. Instrument records suggest that the pressure pulses are generated by ice motion some distance from the instrumented region. Pressure offsets noted in transducer records from Trapridge Glacier indicate pulse magnitudes ranging from $\sim 900 \mathrm{~m}$ to $>1500 \mathrm{~m}$ $(15000 \mathrm{kPa})$. The subsequent basal motion suggested by ploughmeter and geophone records raises the intriguing possibility that the subglacial water system can provide a mechanical teleconnection between regions of the bed that are weakly coupled by longitudinal stresses.

Our laboratory study was performed using two transducers of identical manufacture and thus would be of limited value if other sensors did not fail in a similar manner. Discussions with product engineers at several transducer manufacturers (including Barksdale, Inc., Gems Sensors, Geokon, Inc. and Omega Engineering, Inc.) indicate that pressure transducers that utilize a measurement diaphragm are generally susceptible to similar damage from overpressurization, regardless of the method of diaphragm displacement measurement (e.g. via strain gauges, vibrating wire or solid-state detection). In general, transducer damage can be expected at pressures greater than approximately double the maximum rated pressure, and results in a linear shift in measured pressure. Use of a pulse dampener may prevent damage to transducers if subglacial pressure pulses are of sufficiently short duration $(\sim \mathrm{ms})$ but would obscure the events themselves. Although our laboratory study has reproduced all salient features related to positive jumps in the field records, the testing apparatus used to generate negative damage pressures relies on a vacuum pump and is incapable of producing relative pressures less than $-101 \mathrm{kPa}$ (i.e. $\sim 0$ atm absolute pressure). This magnitude of negative damage pressure is insufficient to cause calibration shift. It is chastening to consider the fact that, examined separately, the pressure records for sensors C2, C3 and U1 would not have been identified as compromised by sensor failure.

\section{ACKNOWLEDGEMENTS}

This research was funded by the Natural Sciences and Engineering Research Council of Canada. We thank Parks Canada for permitting the fieldwork to be conducted in Kluane National Park. G. E. Flowers, K.-N. Foo and D. H. D. Hildes helped with the data collection on Trapridge Glacier; D. Polson and R. Rodway assisted in the design and fabrication of the test equipment. Valuable criticism from R. LeB. Hooke, P. Jansson and an anonymous reviewer improved the quality of this paper.

\section{REFERENGES}

Blake, E.W., U. H. Fischer and G. K. C. Clarke. 1994. Direct measurement of sliding at the glacier bed. F. Glaciol., 40(136), 595-599.

Clarke, G. K. C. 1996. Lumped-element analysis of subglacial hydraulic circuits. 7. Geophys. Res., 101 (B8), 17,547-17,560.

Clarke, G. K. C. and E.W. Blake. 1991. Geometric and thermal evolution of a surge-type glacier in its quiescent state: Trapridge Glacier, Yukon Territory, Canada, 1969-89. f. Glaciol., 37(125), 158-169.

Fischer, U. H. and G. K. C. Clarke. 1994. Ploughing of subglacial sediment. 7. Glaciol., 40(134), 97-106.

Fountain, A. G. 1994. Borehole water-level variations and implications for the subglacial hydraulics of South Cascade Glacier, Washington State, U.S.A. 7. Glaciol., 40(135), 293-304.

Gordon, S., M. Sharp, B. Hubbard, C. Smart, B. Ketterling and I. Willis. 1998. Seasonal reorganization of subglacial drainage inferred from measurements in boreholes. Hydrol. Processes, 12, 105-133.

Murray, T. and G. K. C. Clarke. 1995. Black-box modeling of the subglacial water system. 7. Geophys. Res., 100 (B7), 10,231-10,245.

St. Lawrence, W. and A. Qamar. 1979. Hydraulic transients: a seismic source in volcanoes and glaciers. Science, 203(4381), 654-656.

Stone, D. B. 1993. Characterization of the basal hydraulic system of a surgetype glacier: Trapridge Glacier, 1989-92. (Ph.D. thesis, University of British Columbia.)

Stone, D. B. and G. K. C. Clarke. 1996. In situ measurements of basal water quality and pressure as an indicator of the character of subglacial drainage systems. Hydrol. Processes, 10 (4), 615-628.

Walder, J. S. and A. Fowler. 1994. Channelized subglacial drainage over a deformable bed. f. Glaciol., 40(134), 3-15. 